\title{
Defined Observation Result Derivation
}

\section{Expression}

National Cancer Institute

\section{Source}

National Cancer Institute. Defined Observation Result Derivation Expression. NCI

Thesaurus. Code C93780.

A character string containing a formal language expression that specifies how the observation result's attributes are, should be, or have been derived from input parameters associated with activity. 